\title{
The haematological, proinflammatory cytokines and IgG changes during an ovine experimental theileriosis
}

\begin{tabular}{|c|c|}
\hline \multicolumn{2}{|c|}{$\begin{array}{l}\text { Authors: } \\
\text { Gholamreza Razmi }{ }^{1} \text { (I) } \\
\text { Saeed Yaghfoori }{ }^{1} \text { (D) } \\
\text { Mehrdad Mohri }{ }^{2} \text { (D) } \\
\text { Alirez Haghparast }^{1} \text { (D) } \\
\text { Shahin Tajeri }{ }^{1} \text { (D) }\end{array}$} \\
\hline \multicolumn{2}{|c|}{$\begin{array}{l}\text { Affiliations: } \\
{ }^{1} \text { Department of Pathobiology, } \\
\text { Ferdowsi University of } \\
\text { Mashhad, Islamic Republic } \\
\text { of Iran }\end{array}$} \\
\hline \multicolumn{2}{|c|}{$\begin{array}{l}{ }^{2} \text { Department of Clinical } \\
\text { Sciences, Ferdowsi University } \\
\text { of Mashhad, Islamic Republic } \\
\text { of Iran }\end{array}$} \\
\hline \multicolumn{2}{|c|}{$\begin{array}{l}\text { Corresponding author: } \\
\text { Gholamreza Razmi, } \\
\text { razmi@um.ac.ir }\end{array}$} \\
\hline \multicolumn{2}{|c|}{$\begin{array}{l}\text { Received: } 11 \text { Mar. } 2018 \\
\text { Accepted: } 12 \text { Oct. } 2018 \\
\text { Published: } 04 \text { Feb. } 2019\end{array}$} \\
\hline \multicolumn{2}{|c|}{$\begin{array}{l}\text { How to cite this article: } \\
\text { Razmi, G., Yaghfoori, S., } \\
\text { Mohri, M., Haghparast, A. \& } \\
\text { Tajeri, S., 2019, } \\
\text { 'The haematological, } \\
\text { proinflammatory cytokines } \\
\text { and IgG changes during an } \\
\text { ovine experimental } \\
\text { theileriosis', Onderstepoort } \\
\text { Journal of Veterinary } \\
\text { Research 86(1), a1629. } \\
\text { https://doi.org/10.4102/ojvr. } \\
\text { v86i1.1629 }\end{array}$} \\
\hline \multicolumn{2}{|c|}{$\begin{array}{l}\text { Copyright: } \\
\text { (C) 2019. The Authors. } \\
\text { Licensee: AOSIS. This } \\
\text { is licensed under the } \\
\text { Creative Commons } \\
\text { Attribution License. }\end{array}$} \\
\hline \multicolumn{2}{|l|}{ Read online: } \\
\hline 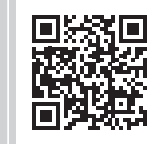 & $\begin{array}{l}\text { Scan this QR } \\
\text { code with your } \\
\text { smart phone or } \\
\text { mobile device } \\
\text { to read online. }\end{array}$ \\
\hline
\end{tabular}

Malignant ovine theileriosis is caused by Theileria lestoquardi, which is highly pathogenic in sheep. Theileriosis involves different organs in ruminants. Little is known about the role of proinflammatory cytokines in the pathogenesis of $T$. lestoquardi infection. The aim of this study was to measure concentration changes of proinflammatory cytokines and immunoglobulin G (IgG) during an ovine experimental theileriosis and correlate it with clinical and haematological parameters. During an experimental study, seven healthy Baluchi sheep (four females and three males) about 6-8 months old were infected with T. lestoquardi by feeding of infected unfed ticks on the sheep's ears. The infected sheep were clinically examined during the study and blood samples were collected on days $0,2,5,7,10,12,14,17$ and 21 . The haematological parameters were analysed by an automatic veterinary haematology cell counter and the inflammatory cytokines interleukin-6 (IL-6), tumour necrosis factor- $\alpha$ (TNF- $\alpha$ ), interferon- $\gamma(\mathrm{IFN}-\gamma)$ and IgG were measured by enzyme-linked immunosorbent assay. All infected sheep had temperatures above $40^{\circ} \mathrm{C}$ on days $3-4$ post infection (PI). The maximum temperature was noted on day 7 , and it remained high until day 21. The parasitaemia of T. lestoquardi infection increased from $0.01 \%$ (day $7 \mathrm{PI}$ ) to $3.3 \%$ (day $21 \mathrm{PI}$ ). The mean white blood cell (WBC), red blood cell (RBC), lymphocyte, neutrophil and platelet values slightly increased on day 2 PI and decreased by day 17 and day 21 PI. The percentage parasitaemia and fever had a negative correlation with the numbers of WBCs, RBCs, lymphocytes, neutrophils and platelets. The serum concentration of IL-6, TNF- $\alpha$ and IFN- $\gamma$ cytokines increased and peaked on day 12 and thereafter decreased to levels lower than 0 . Out of all tested cytokines, the concentration of IL-6 was significantly higher, as early as day 2 PI. No significant changes were observed for the IgG levels during the course of disease. A significant and strong correlation was observed between IL-6, TNF- $\alpha$ and IFN- $\gamma$ values and a moderate correlation between IL-6 and the numbers of lymphocytes in the present study. A strong correlation was determined between the percentage parasitaemia and haematological parameters in T. lestoquardi-infected sheep. In addition, preliminary results indicate that the measurement of the serum concentrations of IL-6 in combination with haematological parameters could be considered a good marker to estimate the pathogenicity of T. lestoquardi strain.

\section{Introduction}

Ovine malignant theileriosis is an important tick-borne disease with high mortality rates. The disease is prevalent in the Middle East, East and North Africa, India, China, Central Asia and Eastern and Southern Europe (Ahmed et al. 2011; Al-Hamidhi et al. 2016; El Imam \& Taha 2015). The agent of disease is T. lestoquardi, which is transmitted by Hyalomma anatolicum ticks. The life cycle of T. lestoquardi is similar to that of T. annulata (Ahmad et al. 2011; Morrison 2015). Briefly, when the ticks suck blood, the sporozoites are inoculated into blood and quickly enter monocytes and lymphocytes of associated lymph nodes near the tick bite. The sporozoites transform to trophozoites and develop to macroschizonts. The macroschizont development causes transformation and proliferation of the infected and non-infected lymphocytes and monocytes. Later, the macroschizonts develop into microschizonts that produce many merozoites in infected lymphocytes or monocytes. The merozoites are released after lymphocyte disruption and enter the erythrocytes and transform to piroplasms with ring, dot and rod forms (Ahmad et al. 2011; Morrison 2015). The pathogenicity of Theileria species is largely related to the ability of Theileria schizonts to induce high proliferation of mononuclear leucocytes and the capacity to metastasise and multiply in non-lymphoid as well as lymphoid tissues (Dobbelaere \& Küenz 2004; Tretina et al. 2015). Some studies have shown that the pathogenesis of acute theileriosis could be related to the high-level production of proinflammatory cytokines during the course of disease in T. annulata-infected cattle (Glass et al. 2000; Graham et al. 2001) and T. parava-infected cattle (Yamada et al. 2009). 
So far, the role of proinflammatory cytokines in the immunopathogenesis of T. lestoquardi infection in sheep has been studied less than that of T. annulata and T. parva infection in cattle. The aim was to measure haematological parameters and proinflammatory cytokines (IL-6, TNF- $\alpha$, IFN- $\gamma$ ) and IgG levels and to determine the correlation of the proinflammatory cytokine levels with haematological parameters during an ovine experimental theileriosis.

\section{Methods}

\section{Experimental transmission}

In this study, seven Baluchi sheep (4 females, 3 males) aged between 6 and 8 months were bought from a farm which had no history of theileriosis. The sheep were experimentally infected with T. lestoquardi as performed previously (Yaghfoori et al. 2016, 2017). Briefly, infected adult H. anatolicum with T. lestoquardi were prepared at the Parasitology Department, Faculty of Veterinary Medicine of the Ferdowsi University of Mashhad, Iran. For experimental transmission of T. lestoquardi, adult ticks of $H$. anatolicum (8 males, 22 females) were placed in cotton bags on the ears of each sheep. All sheep were clinically examined on days $0,2,5,7,10,12,14,17$ and 21 , and the clinical signs recorded. The blood and lymph node smears were simultaneously prepared and thereafter blood samples $(10 \mathrm{~mL})$ were taken from the jugular vein into serum and ethylenediaminetetraacetic acid (EDTA) tubes. The blood and lymph node smears were stained using the Giemsa method. The blood in serum tubes were centrifuged at $\times 1800 \mathrm{~g} \mathrm{rpm}$ for $10 \mathrm{~min}$ and the serum samples were transferred to plain tubes and kept at $-80{ }^{\circ} \mathrm{C}$ until the experiment was performed. The EDTA blood samples were kept at $4{ }^{\circ} \mathrm{C}$ until cell blood count (CBC) examination was performed.

\section{Microscopic examination}

The blood and lymph node smears were stained using the Giemsa method. The stained smears were examined for detection of trophozoites and schizonts of T. lestoqaurdi using a light microscope at $\times 1000$ magnification. The parasitaemia of $T$. lestoquardi infection was determined by counting parasites in 100 microscopic fields in the blood smears (Razmi et al. 2003).

\section{Cell blood count determination}

Total cell counts and differential WBC counts were measured on days $0,2,5,7,10,12,14,17$ and 21 in all sheep with an automatic veterinary haematology cell counter (Nihon Kohden, Celltac $\alpha$, NEK-6450 K, Tokyo, Japan).

\section{Sampling for cytokine measurement}

Commercially available enzyme-linked immunosorbent assay (ELISA) kits (Biotechnology Laboratory, China), including IL- 6 , TNF- $\alpha$, IFN $\gamma$ and IgG, were used to measure respective cytokine and antibody levels according to the manufacturer's instructions. Briefly, flat-bottomed 96-well plates were coated with cytokine-specific monoclonal antibodies labelled with biotin. A volume of $40 \mu \mathrm{L}$ serum sample, $10 \mu \mathrm{L}$ of anticytokine antibody and $50 \mu \mathrm{L}$ of streptavidin-HRP were added to each well and incubated at $37{ }^{\circ} \mathrm{C}$ for $60 \mathrm{~min}$. Each well was washed with washing solution, then $50 \mu \mathrm{L}$ chromogenic solution $\mathrm{A}$ and $50 \mu \mathrm{L}$ chromogen solution B were added and incubated at $37{ }^{\circ} \mathrm{C}$ for $10 \mathrm{~min}$. The reaction was stopped by adding $50 \mu \mathrm{L}$ stop solution and optical density (OD) was read at 450 nanometre $(\mathrm{nm})$ in an ELISA plate reader (ELx800 Absorbance Reader, BioTek, Winooski, VT). Cytokine concentrations (ng/L) were determined by using a standard curve. Detection limits of IL-6, TNF- $\alpha$, IFN $\gamma$ and IgG were $2 \mathrm{ng} / \mathrm{L}-600 \mathrm{ng} / \mathrm{L}$, $5 \mathrm{ng} / \mathrm{L}-400 \mathrm{ng} / \mathrm{L}, 5 \mathrm{ng} / \mathrm{L}-300 \mathrm{ng} / \mathrm{L}$ and $0.02 \mathrm{mg} / \mathrm{mL}-$ $20 \mathrm{mg} / \mathrm{mL}$, respectively.

\section{Statistical analysis}

Results were shown as mean \pm SEM. The Wilcoxon test was used to compare the baseline and next values from the same group of animals. The correlations between different variables were analysed using the Spearman's test (SPSS software version 22). The strength of the correlation between the paired variables is shown as $r_{s}$ value and is by design constrained as follows: $-1 \leq r_{s} \leq 1$. The strength of the correlation is 'very weak' if $r_{s}$ values are between 0.00 and 0.19 , 'weak' if $r_{s}$ values are between 0.20 and 0.39 , 'moderate' if $r_{s}$ values are between 0.40 and 0.59 , 'strong' if $r_{s}$ values are between 0.60 and 0.79 and 'very strong' if $r_{s}$ values are between 0.80 and 1.0. A 'positive correlation' is a relationship between two variables in which both variables move in tandem. A 'negative correlation' is a relationship between two variables that move in opposite directions. The statistical analysis and the tables and chats draws were carried out using SPSS software (version 21). A correlation $p<0.05$ was considered statistically significant.

\section{Ethical considerations}

The experiment was performed according to the internal regulations declared by the Animals Support Association, Ferdowsi University of Mashhad, Iran.

\section{Results}

In this study, all sheep were infected with T. lestoquardi and showed clinical signs, including fever, emaciation, lymph node enlargement, pulmonary and cardiac dysfunction, anaemia, icterus and death. Six infected animals developed acute theileriosis and were euthanised on day 21 PI. One infected animal suddenly died on day 14 PI before it could be euthanised. The body temperature increased above 40 ${ }^{\circ} \mathrm{C}$ on days 3-4 PI and reached a maximum on day $21 \mathrm{PI}$ (Figure 1). Pre-peripheral lymph node enlargement was detected on day 4 PI. Schizonts of T. lestoqaurdi were microscopically detected on day 3 PI and piroplasm formed on day 5 PI. The parasitaemia of T. lestoquardi infection was first detected $(0.01 \%)$ on day 5 PI and reached its highest rate $(3.3 \%)$ on day $21 \mathrm{PI}$ in infected sheep (Figure 1). The mean WBC, RBC, lymphocyte, neutrophil and platelet 
values slightly increased on day 2 PI and thereafter decreased until day 21 PI $(p<0.05)$ (Table 1$)$. The levels of IL-6 were markedly elevated on days 2 PI $(p<0.01)$ and 12 $\mathrm{PI}$, in comparison to the other cytokines, and decreased to levels lower than on day 0 on days 17 and 21 PI $(p<0.05)$ (Table 1). Similar but lower peak levels of TNF- $\alpha$ and INF- $\gamma$ were also observed on day 12 PI which decreased to the lowest level on day 17 and day 21 PI $(p<0.05)$ (Table 1). The mean level of antibody $\operatorname{IgG}$ changes was not significant during the course of the study (Table 1). The serum concentrations of IL- 6 correlated strongly and significantly with the level of TNF- $\alpha$ and IFN- $\gamma$ in serum samples $(p<0.01)$. The correlation between IL-6 and the numbers of lymphocytes was moderate $(p<0.05)$ (Table 2$)$. The percentage parasitaemia and fever had a strong and significant negative correlation with the numbers of neutrophils, WBC, RBC and platelets (Table 2).

\section{Discussion}

There is little information on the mechanism involved in the immunopathogenesis of T. lestoquardi infection despite its

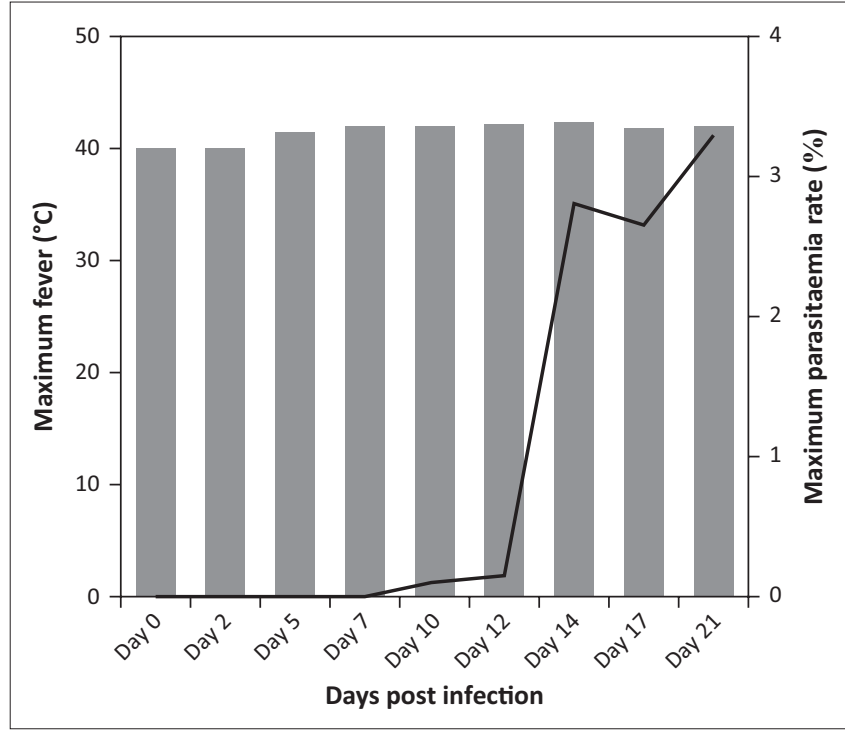

FIGURE 1: Change in body temperature (bar) and percentage of parasitaemia (line) during experimental $T$. lestoquardi infection in sheep. pathogenic nature (Ahmad et al. 2011). In the present study, the haematological, proinflammatory cytokines and IgG parameters were analysed during disease.

During the course of infection, all animals showed a slight leukocytosis at the onset of T. lestoquardi infection, and then the RBC, WBC, neutrophil, lymphocyte and platelet numbers regularly decreased with increased percentage parasitaemia. These results agreed with the results of other authors (Col \& Uslu 2006; Elsadig et al. 2013; Fry et al. 2016; Hasanpour et al. 2008; Leemans et al. 1999; Nazifi et al. 2011; Omer et al. 2002; Sandhu et al. 1998) who reported anaemia, leukopenia, lymphopenia and thrombocytopenia in bovine and ovine theileriosis. The mechanism of anaemia is related to RBC lysis owing to activation of a complement system, erythrophagocytosis and increase in proinflammatory cytokine levels (Graham et al. 2001; Forsyth et al. 1999). In addition, RBC lysis may be the consequence of the damages caused to the RBC membrane because of oxidative stress (Asri Rezaei \& Dalir-Naghadeh 2006; Nazifi et al. 2011, 2013; Razavi et al. 2011). A slight leukocytosis at the onset of infection could be attributed to proliferation of lymphocytes in the lymphoid organs as a defensive response to the Theileria infection. Leukopenia in the terminal stage could have resulted from large-scale destruction of lymphocytes by schizogony in lymphoid organs and infiltration of these cells into various organs (Sandhu et al. 1998). The thrombocytopenia with decreased RBCs and WBCs could also be related to increased TNF- $\alpha$ production (Forsyth et al. 1999) or suppression of the bone marrow by the parasite and its products (Abd Ellah 2015; Mbassa et al. 1994). In this study, the levels of IL-6, TNF- $\alpha$ and IFN- $\gamma$ were increased from the onset to the middle course of disease and decreased in the terminal stage of disease in infected sheep. In vitro studies have reported high mRNA expression levels of proinflammatory cytokines (IL- $1 \beta$, IL-6 and TNF- $\alpha$ ) in leucocytes infected with T. annulata or T. parva schizonts (Brown et al. 1995; Collins et al. 1996; McGuire et al. 2004; Mckeever, Nyanjui \& Ballingall 1997).

Some studies have shown a remarkable elevation in the levels of IL- $1 \beta$, IL-6, IFN- $\gamma$ and TNF- $\alpha$ cytokines in T. annulata-infected cattle (El-Sebaei, El-Ashker \& El-Boshy

TABLE 1: The mean levels of cell blood count, cytokine and antibody concentrations in sheep infected with T. lestoquardi during an experimental study.

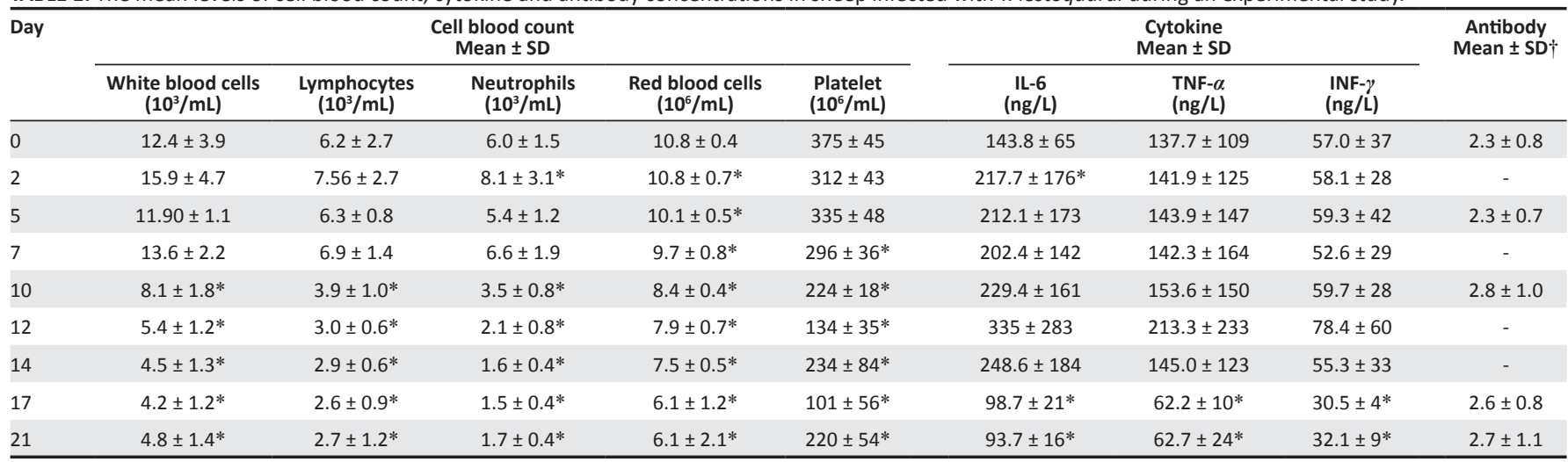

SD, standard deviation; IL-6, interleukin- 6 ; TNF- $\alpha$, tumour necrosis factor- $\alpha$; INF- $\gamma$, interferon- $\gamma$.

$*$, Significant difference with first sampling time at $p<0.05$.

$\dagger, \operatorname{lgG}(\mathrm{mg} / \mathrm{mL})$. 
TABLE 2: Correlation between the mean levels of proinflammatory cytokines, immunoglobulin G, cell blood count, percentage parasitaemia and fever.

\begin{tabular}{|c|c|c|c|c|c|c|c|c|c|c|}
\hline Spearman's rho & $\begin{array}{c}\mathrm{IL}-6 \\
\text { (ng/L) }\end{array}$ & $\begin{array}{l}\text { TNF- } \alpha \\
\text { (ng/L) }\end{array}$ & $\begin{array}{l}\text { IFN- } \gamma \\
\text { (ng/L) }\end{array}$ & $\begin{array}{c}\text { Lymphocytes } \\
(1000 / \mathrm{mL})\end{array}$ & $\begin{array}{c}\text { WBCs } \\
(1000 / \mathrm{mL})\end{array}$ & $\begin{array}{c}\text { Neutrophils } \\
(1000 / \mathrm{mL})\end{array}$ & $\begin{array}{c}\text { RBCs } \\
(1000000 / \mathrm{mL}) \\
\end{array}$ & $\begin{array}{c}\text { Platelet } \\
(1000 / \mu \mathrm{L})\end{array}$ & $\begin{array}{c}\text { Parasitaemia } \\
\text { rate }(\%)\end{array}$ & $\begin{array}{l}\text { Fever } \\
\left({ }^{\circ} \mathrm{C}\right)\end{array}$ \\
\hline \multicolumn{11}{|l|}{ IL-6 (ng/L) } \\
\hline Correlation coefficient & 1.000 & $0.709 * *$ & $0.586 * *$ & $0.277^{*}$ & 0.192 & 0.223 & 0.209 & 0.120 & -0.179 & 0.034 \\
\hline Sig. (2-tailed) & - & 0.000 & 0.000 & 0.032 & 0.141 & 0.086 & 0.113 & 0.367 & 0.170 & 0.796 \\
\hline $\mathrm{N}$ & 61 & 61 & 61 & 60 & 60 & 60 & 59 & 59 & 60 & 60 \\
\hline \multicolumn{11}{|l|}{ TNF- $\alpha$ (ng/L) } \\
\hline Correlation coefficient & $0.709 * *$ & 1.000 & $0.747 * *$ & 0.241 & 0.189 & 0.225 & $0.366^{* *}$ & 0.078 & -0.246 & -0.162 \\
\hline Sig. (2-tailed) & 0.000 & - & 0.000 & 0.063 & 0.148 & 0.085 & 0.004 & 0.557 & 0.058 & 0.217 \\
\hline $\mathrm{N}$ & 61 & 61 & 61 & 60 & 60 & 60 & 59 & 59 & 60 & 60 \\
\hline \multicolumn{11}{|l|}{ IFN- $\gamma$ (ng/L) } \\
\hline Correlation coefficient & $0.586^{* *}$ & $0.747 * *$ & 1.000 & 0.206 & 0.119 & 0.180 & 0.216 & -0.003 & -0.137 & -0.105 \\
\hline Sig. (2-tailed) & 0.000 & 0.000 & - & 0.114 & 0.363 & 0.168 & 0.101 & 0.982 & 0.295 & 0.423 \\
\hline $\mathrm{N}$ & 61 & 61 & 61 & 60 & 60 & 60 & 59 & 59 & 60 & 60 \\
\hline \multicolumn{11}{|l|}{ Lymphocytes (1000/mL) } \\
\hline Correlation coefficient & $0.277^{*}$ & 0.241 & 0.206 & 1.000 & $0.921 * *$ & $0.825^{* *}$ & $0.622^{* *}$ & $0.590 * *$ & $-0.616 * *$ & $-0.386 * *$ \\
\hline Sig. (2-tailed) & 0.032 & 0.063 & 0.114 & - & 0.000 & 0.000 & 0.000 & 0.000 & 0.000 & 0.002 \\
\hline $\mathrm{N}$ & 60 & 60 & 60 & 60 & 60 & 60 & 59 & 59 & 60 & 60 \\
\hline \multicolumn{11}{|l|}{ WBCs $(1000 / \mathrm{mL})$} \\
\hline Correlation coefficient & 0.192 & 0.189 & 0.119 & $0.921 * *$ & 1.000 & $0.940 * *$ & $0.773^{* *}$ & $0.621 * *$ & $-0.753 * *$ & $-0.469 * *$ \\
\hline Sig. (2-tailed) & 0.141 & 0.148 & 0.363 & 0.000 & - & 0.000 & 0.000 & 0.000 & 0.000 & 0.000 \\
\hline $\mathrm{N}$ & 60 & 60 & 60 & 60 & 60 & 60 & 59 & 59 & 60 & 60 \\
\hline \multicolumn{11}{|l|}{ Neutrophils (1000/mL) } \\
\hline Correlation coefficient & 0.223 & 0.225 & 0.180 & $0.825 * *$ & $0.940 * *$ & 1.000 & $0.809 * *$ & $0.549 * *$ & $-0.798 * *$ & $-0.446 * *$ \\
\hline Sig. (2-tailed) & 0.086 & 0.085 & 0.168 & 0.000 & 0.000 & - & 0.000 & 0.000 & 0.000 & 0.000 \\
\hline $\mathrm{N}$ & 60 & 60 & 60 & 60 & 60 & 60 & 59 & 59 & 60 & 60 \\
\hline \multicolumn{11}{|l|}{ RBCs $(1000000 / \mathrm{mL})$} \\
\hline Correlation coefficient & 0.209 & $0.366 * *$ & 0.216 & $0.622 * *$ & $0.773 * *$ & $0.809 * *$ & 1.000 & $0.521 * *$ & $-0.874 * *$ & $-0.676 * *$ \\
\hline Sig. (2-tailed) & 0.113 & 0.004 & 0.101 & 0.000 & 0.000 & 0.000 & - & 0.000 & 0.000 & 0.000 \\
\hline $\mathrm{N}$ & 59 & 59 & 59 & 59 & 59 & 59 & 59 & 59 & 59 & 59 \\
\hline \multicolumn{11}{|l|}{ Platelet } \\
\hline Correlation coefficient & 0.120 & 0.078 & -0.003 & $0.590 * *$ & $0.621 * *$ & $0.549 * *$ & $0.521 * *$ & 1.000 & $-0.497 * *$ & $-0.644 * *$ \\
\hline Sig. (2-tailed) & 0.367 & 0.557 & 0.982 & 0.000 & 0.000 & 0.000 & 0.000 & - & 0.000 & 0.000 \\
\hline $\mathrm{N}$ & 59 & 59 & 59 & 59 & 59 & 59 & 59 & 59 & 59 & 59 \\
\hline \multicolumn{11}{|l|}{ Parasitaemia rate $(\%)$} \\
\hline Correlation coefficient & -0.179 & -0.246 & -0.137 & $-0.616 * *$ & $-0.753 * *$ & $-0.798 * *$ & $-0.874 * *$ & $-0.497 * *$ & 1.000 & $0.591^{* *}$ \\
\hline Sig. (2-tailed) & 0.170 & 0.058 & 0.295 & 0.000 & 0.000 & 0.000 & 0.000 & 0.000 & - & 0.000 \\
\hline $\mathrm{N}$ & 60 & 60 & 60 & 60 & 60 & 60 & 59 & 59 & 60 & 60 \\
\hline \multicolumn{11}{|l|}{ Fever $\left({ }^{\circ} \mathrm{C}\right)$} \\
\hline Correlation coefficient & 0.034 & -0.162 & -0.105 & $-0.386 * *$ & $-0.469 * *$ & $-0.446 * *$ & $-0.676 * *$ & $-0.644 * *$ & $0.591 * *$ & 1.000 \\
\hline Sig. (2-tailed) & 0.796 & 0.217 & 0.423 & 0.002 & 0.000 & 0.000 & 0.000 & 0.000 & 0.000 & - \\
\hline $\mathrm{N}$ & 60 & 60 & 60 & 60 & 60 & 60 & 59 & 59 & 60 & 60 \\
\hline
\end{tabular}

IL-6, interleukin-6; TNF- $\alpha$, tumour necrosis factor- $\alpha$; IFN- $\gamma$, interferon- $\gamma$; WBCs, white blood cell; RBCs, red blood cell.

*, Correlation is significant at the 0.05 level (2-tailed); **, Correlation is significant at the 0.01 level (2-tailed).

2014; Razavi et al. 2010; Nazifi et al. 2010) and T. lestoquardinfected sheep (Razavi et al. 2015) in farm conditions. Despite the high correlation observed between IL- 6 levels with TNF- $\alpha$ and INF- $\gamma$ levels during the course of disease, only IL-6 was significantly increased. The sources of IL- 6 are monocytes and macrophages. The crucial role of IL-6 is B- and T-cell activation and the induction of the acute phase response (Hunter \& Jones 2015; Tanaka \& Kishimoto 2012). During acute inflammation, IL-6 is the first responding cell factor which will induce the generation of C-reactive protein (CRP), serum amyloid A, fibrinogen and hepcidin in hepatocytes (Reinhart et al. 2012; Tanaka, Narazaki \& Kishimoto 2014). IL-6 has a longer plasma half-life than TNF- $\alpha$ or IL- $1 \beta$ and is more reliably measurable in plasma than the other two cytokines. It also has other potential clinical uses, such as diagnosis and management of autoimmune rheumatic disorders. Its major role as a biomarker of sepsis appears to be prognostic, and not diagnostic
(Faix 2013; Reinhart et al. 2012). A correlation between high levels of IL-6 with mortality rate has been reported in systemic bacterial infection in humans and dogs (Nijsten et al. 1978; Oda et al. 2005; Rau et al. 2007), in malaria (Day et al. 1999; Mbengue et al. 2015) and canine babesiosis (Goddard et al. 2016). The role of IL-6 in immunopathogenesis of theileriosis is unclear. Some studies have shown that high IL-6 expression was related to virulence of Theileria strains and host susceptibility (McKeever, Nyanjui \& Ballingall 1997; Yamada et al. 2009), and non-detectable IL-6 expression correlated with resistance of sheep to T. annulata (Schnittger et al. 2000) and African buffaloes to T. parva (Okagawa et al. 2012).

\section{Conclusion}

Based on the results, the WBC, RBC, lymphocyte, neutrophil and platelet values decreased with increased percentage 
parasitaemia and temperature during the course of T. lestoquardi infection in sheep. In addition, a high correlation was observed between serum levels of IL- 6 with levels of TNF- $\alpha$ and INF- $\gamma$. Preliminary results indicate that the measurement of the serum concentrations of IL-6 cytokine in combination with haematological parameters could be considered a good marker to estimate the pathogenicity of the T. lestoquardi strain.

\section{Acknowledgements Competing interests}

The authors declare that they have no financial or personal relationships that may have inappropriately influenced them in writing this article.

\section{Authors' contributions}

G.R. was the leader of project. He did microscopic examination, analysed the data and wrote the manuscript. S.Y. clinically examined the sheep, collected blood samples and performed ELISA examination. M.M. performed haematological examination. A.H. analysed the immunology results. S.T. helped S.Y. to do the experimental transmission of Theileria lestoquardi by ixodid ticks. All the authors contributed to the revision and final approval of the manuscript.

\section{Funding information}

This study was supported by a grant from the Vice President Research and Technology of Ferdowsi University of Mashhad, Iran (grant no. VPRTFM-1.37336).

\section{References}

Abd Ellah, M.R., 2015, 'Studying the correlations among hematological and serum biochemical constituents in cattle theileriosis', Journal of Parasitic Diseases 39 , 134-139. https://doi.org/10.1007/s12639-013-0299-0

Ahmed, J., Yin, H., Bakheit, M., Liu, Z., Mehlhorn, H. \& Seitzer, U., 2011, 'Small ruminant theileriosis', in $\mathrm{H}$. Mehlhorn (ed.), Progress in parasitology, pp. 135-153, Springer, Berlin.

Al-Hamidhi, S., Weir, W., Kinnaird, J., Tageledin, M., Beja-Pereira, A., Morrison, I. et al 2016 , 'Theileria lestoquardi displays reduced genetic diversity relative to sympatric 2016, 'Theileria lestoquardi displays reduced genetic diversity relative to sympatric
Theileria annulata in Oman', Infection, Genetics and Evolution 43, 297-306. Theileria annulata in Oman', Infection, Genetics
https://doi.org/10.1016/j.meegid.2016.05.007

Asri Rezaei, S. \& Dalir-Naghadeh, B., 2006, 'Evaluation of antioxidant status and oxidative stress in cattle naturally infected with Theileria annulata', Veterinary Parasitology 142, 179-186. https://doi.org/10.1016/j.vetpar.2006.05.033

Brown, D.J., Campbell, J.D.M., Russell, G.C., Hopkins, J. \& Glass, E.J., 1995, 'T cell activation by Theileria annulata-infected macrophages correlates with cytokine production', Clinical Experimental Immunology 102, 507-514.

Col, R. \& Uslu, U., 2006, 'Hematological and coagulation profiles during severe tropical theileriosis in cattle', Turkish Journal of Veterinary and Animal Sciences 30, 577-582. https://doi.org/10.1111/j.1365-2249.1995.tb03845.x

Collins, R.A., Sopp, P., Gelder, K.I., Morrison, W.I. \& Howard, C.J., 1996, 'Bovine $\gamma / \delta$ $\mathrm{TCR}^{+} \mathrm{T}$ lymphocytes are stimulated to proliferate by autologous Theileria annulata-infected cells in the presence of interleukin-2', Scandinavian Journalof Immunology44,444-452. https://doi.org/10.1046/j.1365-3083.1996. d01-332.x

Day, N.P., Hien, T.T., Schollaardt, T., Loc, P.P., Chuong, L.V., Chau, T.T. et al., 1999, 'The prognostic and pathophysiologic role of pro- and antiinflammatory cytokines in severe malaria', Journal of Infection Diseases 180, 1288-1297. https://doi. org/10.1086/315016

Dobbelaere, D.A. \& Küenzi, P., 2004, 'The strategies of the Theileria parasite: A new twist in host-pathogen interactions', Current Opinion in Immunology 16, 524-530. https://doi.org/10.1016/j.coi.2004.05.009

El Imam, A.H. \& Taha, K.M., 2015, 'Malignant ovine theileriosis (Theileria lestoquardi): A review', Jordan Journal of Biological Sciences 8, 165-174. https://doi.org/ 10.12816/0026953
Elsadig, A.A., Elmansoury, Y.H.A., Babiker, A.A.A., Abdelmageed, T.O. \& Hussein, S., 2013, 'Effects of Theileria lestoquardi infection on haematological and biochemical parameters in experimentally infected desert ewes', Jordan Journal of Biological parameters in experimentally infected desert ewes', Jor
Sciences 6, 316-319. https://doi.org/10.12816/0001631

El-Sebaei, M., El-Ashker, M. \& El-Boshy, M., 2014, 'The role of acute phase cytokines in the recovery and disease progress of Theileria annulata-infected cattle', Comparative Clinical Pathology 23, 1497-1502. https://doi.org/10.1007/s00580013-1812-7

Faix, J.D., 2013, 'Biomarkers of sepsis', Critical Reviews in Clinical Laboratory Sciences $50,23-36$.

Forsyth, L.M., Minns, F.C., Kirvar, E., Adamson, R.E., Hall, F.R., McOrist, S. et al., 1999, 'Tissue damage in cattle infected with Theileria annulata accompanied by metastasis of cytokine-producing, schizont-infected mononuclear phagocytes', Journal of Comparative Pathology 120, 39-57.

Fry, L.M., Schneider, D.A., Frevert, C.W., Nelson, D.D., Morrison, W.I. \& Knowles, D.P., 2016 'East coast fever caused by Theileria parva is characterized by macrophage activation associated with vasculitis and respiratory failure', PLOS One 11(5), e0156004.

Goddard, A., Leisewitz, A.L., Kjelgaard-Hansen, M., Kristensen, A.T. \& Schoeman, J.P., 2016 'Excessive pro-inflammatory serum cytokine concentrations in virulent canine babesiosis', PLoS One 11(3), e0150113. https://doi.org/10.1371/journal.pone.0150113

Glass, E.J., Craigmile, S.C., Springbett, A., Preston, P.M., Kirvar, E., Wilkie, G.M. et al., 2000, 'The protozoan parasite, Theileria annulata, induces a distinct acute phase protein response in cattle that is associated with pathology', International Journal for Parasitology 33, 1409-1418. https://doi.org/10.1016/S0020-7519(03)00166-8

Graham, S.P., Brown, D.J., Vatansever, Z., Waddington, D., Taylor, L.H., Nichani, A.K. et al., 2001, 'Proinflammatory cytokine expression by Theileria annulata infected cell lines correlates with the pathology they cause in vivo', Vaccine 19, 2932-2944. https://doi.org/10.1016/S0264-410X(00)00529-6

Hasanpour, A., Moghaddam, G.A. \& Nematollahi, A., 2008, 'Biochemical, hematological, and electrocardiographic changes in buffaloes naturally infected with Theileria annulata', Korean Journal of Parasitology 46, 223-227. https://doi. org/10.3347/kjp.2008.46.4.223

Hunter, C.A. \& Jones, S.A., 2015, 'IL-6 as a keystone cytokine in health and disease', Nature Immunology 16, 448-457. https://doi.org/10.1038/ni.3153

Leemans, I., Brown, D., Hooshmand-Rad, P., Kirvar, E. \& Uggla, A., 1999, 'Infectivity and cross-immunity studies of Theileria lestoquardi and Theileria annulata in sheep and cattle: I. In vivo responses', Veterinary Parasitology 82, 179-192. https://doi.org/10.1016/S0304-4017(99)00013-8

Mbassa, G.K., Balemba, O., Maselle, R.M. \& Mwaga, N.V., 1994, 'Severe anaemia due to haematopoietic precursor cell destruction in field cases of East Coast Fever in Tanzania', Veterinary Parasitology 52, 243-256. https://doi.org/10.1016/0304Tanzania', Veterinary
4017(94)90116-3

Mbengue, B., Niang, B., Niang, M.S., Varela, M.L., Fall, B., Fall, M.M. et al., 2015 , 'Inflammatory cytokine and humoral responses to Plasmodium falciparum glycosylphosphatidylinositols correlates with malaria immunity and pathogenesis', glycosylphosphatidylinositols correlates with malaria immunity and pathogenesis',
Immunity, Inflammation and Disease 4, 24-34. https://doi.org/10.1002/iid3.89

McGuire, K., Manuja, A., Russell, G.C., Springbett, A., Craigmile, S.C., Nichani, A.K. et al., 2004, 'Quantitative analysis of pro-inflammatory cytokine mRNA expression
in Theileria annulata infected cell lines derived from resistant and susceptible cattle', Veterinary Immunology and Immunopathology 99, 87-98. https://doi. cattle, Veterinary Immunology and In
org/10.1016/j.vetimm.2004.01.003

McKeever, D.J., Nyanjui, J.K. \& Ballingall, K.T., 1997, 'In vitro infection with Theileria parva is associated with IL10 expression in all bovine lymphocyte lineages', Parasite Immunology 19, 319-324. https://doi.org/10.1046/j.1365-3024.1997.d01-214.x

Morrison, W.I., 2015, 'The aetiology, pathogenesis and control of theileriosis in domestic animals', Revue Scientifique et Technique 34, 599-611. https://doi org/10.20506/rst.34.2.2383

Nazifi, S., Razavi, S., Reiszadeh, M., Esmailnezhad, Z. \& Ansari-Lari, M., 2010 'Diagnostic values of acute phase proteins in Iranian indigenous cattle infected with Theileria annulata', Veterinarski Arhiv 80, 205-214.

Nazifi, S., Razavi, S.M., Kianiamin, P. \& Rakhshandehroo, E., 2011, 'Evaluation of erythrocyte antioxidant mechanisms: Antioxidant enzymes, lipid peroxidation and serum trace elements associated with progressive anemia in ovine malignant serum trace elements associated with progressive anemia in ovine malignant
theileriosis', Parasitology Research 109, 275-281. https://doi.org/10.1007/ theileriosis', Parasits
s00436-010-2248-5

Nazifi, S., Razavi, S.M., Rakhshandehroo, E., Sadoughifar, R. \& Sharifian, M., 2013 'Ovine malignant theileriosis: The status of antioxidant vitamins, serum lipid profile, lipid peroxidation and erythrocyte antioxidant defense', Comparative profile, lipid peroxidation and erythrocyte antioxidant defense', Comparal
Clinical Pathology 22, 379-385. https://doi.org/10.1007/s00580-012-1419-4

Nijsten, M.W., De Groot, E.R., Ten Duis, H.J., Klasen, H.J., Hack, C.E. \& Aarden, L.A., 1987, 'Serum levels of interleukin-6 and acute phase responses', Lancet 2, 921. https://doi.org/10.1016/S0140-6736(87)91413-9

Oda, S., Hirasawa, H., Shiga, H., Nakanishi, K., Matsuda, K. \& Nakamua, M., 2005, 'Sequential measurement of IL-6 blood levels in patients with systemic inflammatory response syndrome (SIRS)/sepsis', Cytokine 29, 169-175. https:// doi.org/10.1016/j.cyto.2004.10.010

Okagawa, T., Konnai, S., Mekata, H., Githaka, N., Suzuki, S., Kariuki, E. et al., 2012, 'Transcriptional profiling of inflammatory cytokine genes in African buffaloes (Syncerus caffer) infected with Theileria parva', Veterinary Immunology and Immunopathology 148, 373-379. https://doi.org/10.1016/j.vetimm.2012.06.015

Omer, O.H., El-Malik, K.H., Mahmoud, O.M., Haroun, E.M., Hawas, A., Sweeney, D. et al., 2002, 'Haematological profiles in purebred cattle naturally infected with Theileria annulata in Saudi Arabia', Veterinary Parasitology 107, 161-168. https:// doi.org/10.1016/S0304-4017(02)00094-8

Reinhart, K., Bauer, M., Riedemann, N.C. \& Hartoga, C.S., 2012, 'New approaches to sepsis: Molecular diagnostics and biomarkers', Clinical Microbiology Review 25, 609-634. https://doi.org/10.1128/CMR.00016-12 
Rau, S., Kohn, B., Richter, C., Fenske, N., Küchenhoff, H., Hartmann, K. et al., 2007 'Plasma interleukin-6 response is predictive for severity and mortality in canine systemic inflammatory response syndrome and sepsis', Veterinary Clinical systemic inflammatory response syndrome and sepsis', Veterinary Clinical
Pathology 36, 253-260. https://doi.org/10.1111/j.1939-165X.2007 .tb00220.x

Razavi, S.M., Espandarnia, A., Rakhshandehroo, E., Ghane, M. \& Nazifi, S., 2015 'Malignant ovine theileriosis: Serum concentrations of some inflammatory components and adenosine deaminase activity', Comparative Clinical Pathology 24, 639-643. https://doi.org/10.1007/s00580-014-1959-x

Razavi, S.M., Nazifi, S., Bateni, M. \& Rakhshandehroo, E., 2011, 'Alterations of erythrocyte antioxidant mechanisms: Antioxidant enzymes, lipid peroxidation and serum trace elements associated with anemia in bovine tropical theileriosis', Veterinary Parasitology 180, 209-214. https://doi.org/10.1016/j.vetpar.2011.03.011

Razavi, S.M., Nazifi, S., Emadi, M. \& Rakhshandehroo, E., 2010, 'The correlations among serum tumor necrosis factor- $\alpha$ (TNF- $\alpha$ ), interferon- $\gamma$ (IFN- $\gamma$ ) and sialic acids with peripheral lymphocytes in bovine tropical theileriosis', Veterinary Research and Communications 34, 579-587. https://doi.org/10.1007/s11259010-9429-7

Razmi, G.R., Hosseini, M. \& Aslani, M.R., 2003, 'Identification of tick vectors of ovine theileriosis in an endemic region of Iran', Veterinary Parasitology 116, 1-6. https://doi.org/10.1016/S0304-4017(03)00254-1

Sandhu, G.S., Grewal, A.S., Singh, A., Kondal, J.K., Singh, J. \& Brar, R.S., 1998 'Haematological and biochemical studies on experimental Theileria annulato infection in crossbred calves', Veterinary Research and Communications 22, 347-354. https://doi.org/10.1023/A:1006129306093
Schnittger, L., Hollmann, C., Diemer, U., Boguslawski, K. \& Ahmed, J.S., 2000, 'Proliferation and cytokine profile of $T$. annulata-infected ovine, caprine, and bovine lymphoblastoid cells', Annals of the New York Academy of Sciences 916 676-680. https://doi.org/10.1111/j.1749-6632.2000.tb05360.x

Tanaka, T. \& Kishimoto, T., 2012, 'Targeting interleukin-6: All the way to treat autoimmune and inflammatory diseases', International Journal of Biological Sciences 8, 1227-1236. https://doi.org/10.7150/ijbs.4666

Tanaka, T., Narazaki, M. \& Kishimoto, T., 2014, 'IL-6 in inflammation, immunity, and disease', Cold Spring Harbor Perspectives in Biology 6, a016295. https://doi. org/10.1101/cshperspect.a016295

Tretina, K., Gotia, H.T., Mann, D.J. \& Silva, J.C., 2015, 'Theileria-transformed bovine leukocytes have cancer hallmarks', Trends in Parasitology 31, 306-314. https:// doi.org/10.1016/j.pt.2015.04.001

Yamada, S., Konnai, S., Imamura, S., Simuunza, M., Chembensofu, M., Chota, A. et al., 2009, 'Quantitative analysis of cytokine mRNA expression and protozoan DNA load in Theileria parva-infected cattle', Journal of Veterinary Medical Science 71, 49-54. https://doi.org/10.1292/jvms.71.49

Yaghfoori, S., Mohri, M. \& Razmi, G., 2017, 'Experimental Theileria lestoquard infection in sheep: Biochemical and hematological changes', Acta Tropica 173, 55-61. https://doi.org/10.1016/j.actatropica.2017.05.029

Yaghfoori, S., Razmi, G.R., Mohri, M., Razavizadeh, A.R. \& Movassaghi, A.R., 2016, 'An experimental ovine Theileriosis: The effect of Theileria lestoquardi infection on cardiovascular system in sheep', Acta Tropica 161, 55-61. https://doi. org/10.1016/j.actatropica.2016.05.014 